\title{
Gemcitabine/cisplatin versus 5-fluorouracil/ mitomycin C chemoradiotherapy in locally advanced pancreatic cancer: a retrospective analysis of 93 patients
}

Thomas B Brunner ${ }^{1,2^{*}}$, Rolf Sauer ${ }^{1}$ and Rainer Fietkau ${ }^{1}$

\begin{abstract}
Background: Despite of a growing number of gemcitabine based chemoradiotherapy studies in locally advanced pancreatic cancer (LAPC), 5-fluorouracil based regimens are still regarded to be standard and the debate of superiority between the two drugs is going on. The aim of this retrospective analysis was to evaluate the effect of two concurrent chemoradiotherapy regimens using 5-fluorouracil or gemcitabine to compare their effect and tolerance.

Methods: We have performed a single centre retrospective analysis of 93 patients treated with conventionally fractionated radiotherapy of 55.8 Gray using either concurrent 5-fluorouracil, $1 \mathrm{~g} / \mathrm{m}^{2}$ on days $1-5$ and 29-33 of radiotherapy and $10 \mathrm{mg} / \mathrm{m}^{2}$ of mitomycin C on day 1, 29 of radiotherapy (FM group, 35 patients) versus gemcitabine $\left(300 \mathrm{mg} / \mathrm{m}^{2}\right)$ and cisplatin, $\left(30 \mathrm{mg} / \mathrm{m}^{2}\right)$ on days 1, 8, 22, and 29 (GC group, 58 patients). Primary endpoint was the median overall survival (OS) rate.
\end{abstract}

Results: The median OS rate was 12.7 months in the GC group and 9.7 months in the FM group. The 1-year OS rate was 53\% versus $40 \%$, respectively $(p=0.009$ ). GC led to more grade 3 leukocytopenia and thrombocytopenia than FM, but not to more grade 4 myelosuppression. Thrombocytopenia was the most frequently observed grade 4 toxicity in both groups (11\% after FM versus 12\% after GC). No grade 3/4 febrile neutropenia was observed. Grade 3 nausea was more common in the FM group (20\% versus 9\%) and grade 4 nausea was observed in one patient per group only.

Conclusions: GC was superior to FM for overall survival and both regimens were similar in terms of tolerance. We conclude that GC leads to encouraging results and that the use of FM for chemoradiotherapy in LAPC cannot be recommended without concerns.

Keywords: Pancreatic cancer, chemoradiotherapy, gemcitabine, 5-fluorouracil

\section{Background}

Pancreatic ductal adenocarcinoma (PDAC), commonly known as pancreatic cancer, is the $10^{\text {th }}$ most common cancer type with an incidence of 10/100,000 but highly lethal (>95\%) and this is reflected by the fact that it is ranking as the $5^{\text {th }}$ most lethal cancer in absolute patient numbers after lung, colorectal, breast and prostate

\footnotetext{
* Correspondence: thomas.brunner@rob.ox.ac.uk

'Radiation Oncology of the Friedrich-Alexander University of Erlangen-

Nuremberg, Universitätsstraße 22, 91054 Erlangen, Germany

Full list of author information is available at the end of the article
}

cancer $[1,2]$. Due to the declines in lethality in other major cancers, pancreatic cancer is predicted to become the fourth cause of cancer death in Europe [2]. Dramatic progress was made during the past years to better understand the biology of this disease (reviewed in [3]). Only $10-20 \%$ of the patients have resectable tumours at diagnosis and resection is a prerequisite for cure but even with adjuvant therapy median overall survival of resected patients is still as low as $20 \%$ after 5 years in randomised phase III studies (reviewed in [4]). The large majority (> 80\%) of patients with non-resectable disease 
at diagnosis can be subdivided into metastatic and locally advanced PDAC (LAPC) with both stages being about equally frequent. Compared with metastatic disease patients with LAPC have a better prognosis and though often grouped together with metastatic disease not separated in randomised phase III trials - patients with LAPC should be separated from patients with metastatic disease.

Chemotherapy is an essential element in the treatment of LAPC to fight the high tendency of distant spread. But the combination of systemic with local treatment prolonged survival in a number of recent studies $[5,6]$ compared with systemic therapy only. Of note, secondary resection after CRT was reported in a systematic review and meta-analysis in $1 / 3$ of the patients leading to a median overall survival (mOS) rate of 20.5 months which is equally good as after primary resection [7] and downstaging was also described [8]. On the other hand, the inferiority of chemoradiotherapy (CRT) vs chemotherapy in a recent French trial [9] can most likely be attributed to inadequate technique and quality of chemoradiotherapy highlighting the complexities of CRT for PDAC [10]. Of note, 60 Gy were delivered in 2 Gy fractions to both the primary tumour and the elective lymphatics resulting in large planning target volumes (PTV) as $2 \mathrm{~cm}$ expansion margins were used from the clinical target volumes. Also, the FFCD-SFRO trial [9] is the only randomised phase III CRT trial using 5-fluorouracil (5-FU)/Cisplatin as concurrent chemotherapeutic agents and this resulted in a very high rate of grade 3/4 toxicity for the adjuvant chemotherapy and prevented maintenance chemotherapy. Commonly, the combination of a fluoropyrimidine with radiotherapy is regarded to be the standard of care for CRT [4] but a substantial number of gemcitabine based CRT trials was reported with encouraging results such as in the ECOG4201 trial [6]. The latter trial used IMRT together with $600 \mathrm{mg} / \mathrm{m}^{2}$ gemcitabine weekly, a relatively high dose, resulting in a high rate of grade $3 / 4$ toxicity.

The rationale for preferring gemcitabine over $5-\mathrm{FU}$ in CRT regimens is its hypothesised superiority both, locally and systemically: in metastatic disease gemcitabine was able to prolong survival and to lead to higher clinical benefit compared to 5-FU [11]. For the local effect when used with radiotherapy, gemcitabine is predicted to lead to higher tumour cytotoxicity than 5-FU because it is one of the most potent radiosensitising chemotherapeutic agents [12]. Gemcitabine is an Sphase specific deoxycytidine analogue. It acts via competitive incorporation of dFdCTP and dCTP into DNA and results in DNA fragmentation and subsequent cell death. Furthermore, gemcitabine interferes with ribonucleotide reductase which is thought to have an impact on cell death by affecting DNA repair. Also, specific single-nucleotide polymorphisms in DNA the repair damage genes ATM, Chek1 and ATR were found to be significantly associated with OS after gemcitabine CRT especially when analysed for the combined effect of all three genes [13]. In line with these observations, gemcitabine containing schedules were described to achieve a higher rate of pathologic response compared to 5 -FU based protocols [14]. The combination of gemcitabine with 5-FU or capecitabine which is commonly used as a chemotherapy combination was found to be too toxic for CRT in LAPC especially in terms of elevated gastrointestinal toxicity [15]. Therefore we decided a different chemotherapeutic combination, gemcitabine and cisplatin, which had been investigated both preclinically and clinically: the synergism between the two drugs is attributed mainly to an increase in platinum-DNA adduct formation which is possibly related to changes in DNA due to $\mathrm{dFdC}$ incorporation into the DNA [16-18]. The combination of the two drugs is clinically in use mainly in ovarian, non-small cell lung and pancreatic cancer and has been more effective than gemcitabine only in metastatic and locally advanced PDAC in the group of patients with good performance status [19].

Despite of this rationale, gemcitabine initially was difficult to be combined with radiotherapy due to its acute toxicity profile depending profoundly on the absolute radiotherapy treatment volume $[18,20]$. This potential dangerous effect can now be more easily counterbalanced with highly conformal treatment planning and the use of IMRT/IGRT thereby increasing the tolerance of gemcitabine based CRT [21]. In this analysis we compare the outcome and the toxicity of two CRT regimens in 93 patients with LAPC treated at our centre: One regimen was 5-FU/Mitomycin $\mathrm{C}(\mathrm{FM})$, the other gemcitabine/cisplatin (GC) given concurrently with radiotherapy. These two regimens have not been compared in the literature up to now but they both have been used in a number of trials in PDAC and other upper GI tumours [22-25]. We report superior OS of the GC regimen with comparable high grade toxicity (grade 4 haematologic and grade 3/4 non-haematologic disease).

\section{Methods}

\section{Patient population}

This is a retrospective study identifying all patients treated at the University Hospitals of Erlangen with chemoradiotherapy. Patients were identified by reviewing the tumour board minutes and the departmental minutes of Radiation Oncology. Patients with locally advanced pancreatic carcinoma (LAPC) were selected for primary CRT at our local tumour board. The following eligibility criteria were used: Histological proof of ductal adenocarcinoma prior to CRT. In general, LAPC was defined along the lines of the Practice Guidelines in Oncology ${ }^{\mathrm{TM}}$ 
of the National Comprehensive Cancer Network [26]: A minimal Karnofsky performance score $\geq 60 \%$ was required and pretherapeutic laboratory requirements for chemotherapy were: leukocyte count $\geq 4000 / \mu \mathrm{L}$, platelet count $\geq 100,000 / \mu \mathrm{L}$, bilirubin $<2.0 \mathrm{mg} / \mathrm{dL}$, and a creatinine clearance $\geq 60 \mathrm{~mL} / \mathrm{min}$. Echocardiography was performed to ensure that prehydration before cisplatin chemotherapy was tolerable. Jaundiced patients underwent bile duct stenting prior to therapy. Patients being treated with either FM or GC chemotherapy were eligible. These two schedules were used almost exclusively in our institution. Choice between FM and GC is explained below.

\section{Treatment}

Radiation treatment planning was performed as described elsewhere in detail [27]. Briefly, 3-D conformal treatment planning was applied based on IV and oral contrast enhanced planning CT scans. PTV_5040 (planning target volume) comprised the primary tumour (GTV) and elective lymphatic nodes and PTV_5580 comprised the GTV with margins only. Elective nodes treated in pancreatic head and body tumours were the regions $8,9,12,13,14,16 \mathrm{a} 2,16 \mathrm{~b} 1$, 17 , and 18 to the right of the left edge of the aorta according to the Japanese Gastric Cancer Association [28]. The total PTV_5040 volume was not allowed to be larger than $800 \mathrm{~mL}$. Conventional fractionation with single doses of 1.8 Gy was used. The dose constraints for the organs at risk were for the liver V30 < $50 \%$, for the ipsilateral kidney V20 $<50 \%$ and for the contralateral kidney $\mathrm{V} 20<30 \%$, and $\mathrm{D}_{\max }$ to the spinal cord < $40 \mathrm{~Gy}$.

For the 5-fluorouracil and Mitomycin $\mathrm{C}$ regimen (FM), 5-FU was given as $24 \mathrm{~h}$ continuous infusion of $1000 \mathrm{mg} / \mathrm{m} 2 /$ day on days 1-5 and days 29-33. Mitomycin $\mathrm{C}$ was given as an IV bolus injection $(10 \mathrm{mg} / \mathrm{m} 2)$ on days 1 and 29 (Figure 1). For the gemcitabine/Cisplatin (GC) regimen, $300 \mathrm{mg} / \mathrm{m} 2$ gemcitabine and 30 $\mathrm{mg} / \mathrm{m} 2$ cisplatin were given intravenously on days 1,8 , 22 and 29 being the first day of radiotherapy in weeks 1, 2, 4 and 5. Gemcitabine was given first followed immediately by Cisplatin which was given $<1$ hour prior to radiotherapy. Supportive therapy comprised gastric acid protection during and at least 3 months after therapy, antiemetic therapy, and nutritional support which in most patients was given as supportive parenteral feeding as required. There was a gradual change in the institution from FM to GC after the completion of a phase I study on concurrent GC chemoradiotherapy [29]. After chemoradiotherapy some patients had additive gemcitabine chemotherapy (1000 $\mathrm{mg} / \mathrm{kg}$; d1, 8, 15, q29d) which was given at the discretion of the treating physician.

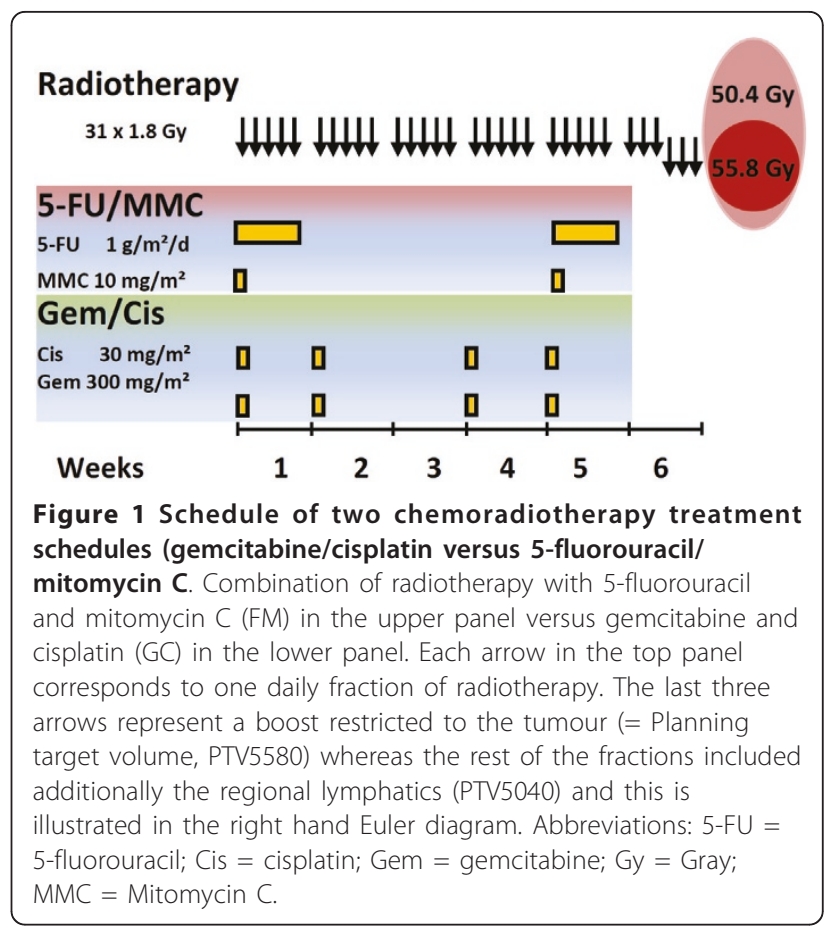

\section{Efficacy, treatment evaluation and statistical analysis}

Follow up examinations were performed six weeks after the end of treatment and then every 3 months for the first 2 years after chemoradiotherapy and thereafter every 6 months for at least 3 years. In addition to physical examination, laboratory tests (full blood cell counts, biochemistry including liver and kidney function tests and CA-19-9), and ultrasound of the abdomen. CT abdomen and a chest X-ray or a CT abdomen/chest were performed every 6 months. Statistical data analysis was done with the software IBM Statistical Package for the Social Sciences ${ }^{\circledR}$, version 19.0. Kaplan-Meier plots were calculated for analysis of survival. Survival was calculated from date of diagnosis to date of death or date of last contact. Pair wise log-rank test was employed for comparison of the differences in survival in subgroups of patients. The RTOG toxicity criteria [30], the LENTSOMA criteria [31] (side effects of radiotherapy) and the CTCAE v3.0 toxicity criteria of the NCI (haematological side effects) were used to classify acute and chronic treatment-related side effects. The treatment was in accordance with the ethical standards of the local committee on human experimentation and with the Helsinki Declaration of 1975, as revised in 2000, and all patients provided informed consent before therapy.

\section{Results}

\section{Patient characteristics}

Ninety-three patients from our centre were treated with either FM or with GC chemoradiotherapy. The median 
follow-up time at analysis was 11.7 months. At the time of analysis 6 patients were alive (6\%). The baseline patient characteristics are summarised in Table 1 . The majority of the patients were diagnosed with cT4 tumours (52\%). In both arms, $91 \%$ of the patients had an ECOG performance status of at least 2, respectively. All patients had ductal adenocarcinoma of the pancreas as diagnosed by biopsy or laparoscopically during an attempt of resection. Reasons for non-resectability were vascular involvement in most patients or nodal disease as diagnosed on contrast enhanced computed tomography.

\section{Treatment and outcome}

The median duration of radiotherapy was 43 days (SD 4.8 days) in all patients (FM, 43 days, SD 5.2 days; GC, 42 days, SD 4.9 days). In the FM group and in the GC group the median total doses to the PTV_5040 (primary and lymphatics) were 50.4 Gy (range 28.8 - 50.8 Gy; 41.4 - 55.8 Gy) and the cumulative doses to the

Table 1 Patient characteristics

\begin{tabular}{|c|c|c|c|c|c|}
\hline & & \multicolumn{2}{|c|}{$\begin{array}{c}\text { 5-FU, } \\
\text { Mitomycin C }\end{array}$} & \multicolumn{2}{|c|}{$\begin{array}{c}\text { Gemcitabine, } \\
\text { Cisplatin }\end{array}$} \\
\hline & & patients & $\%$ & patients & $\%$ \\
\hline All patients & & \multicolumn{2}{|l|}{35} & \multicolumn{2}{|l|}{58} \\
\hline Age & Median (Range) & \multicolumn{2}{|c|}{$63(37-75)$} & \multicolumn{2}{|c|}{$63(35-76)$} \\
\hline \multirow[t]{2}{*}{ Gender } & Male & 23 & 66 & 36 & 62 \\
\hline & Female & 12 & 34 & 22 & 38 \\
\hline \multirow[t]{2}{*}{ Surgery } & No resection & 26 & 74 & 41 & 71 \\
\hline & resection & 9 & 26 & 15 & 29 \\
\hline \multirow[t]{5}{*}{ Tumour location } & Head & 25 & 71 & 40 & 69 \\
\hline & Head/Body & 3 & 9 & 5 & 9 \\
\hline & Body & 5 & 14 & 9 & 16 \\
\hline & Body and tail & 1 & 3 & 3 & 5 \\
\hline & tail & - & - & 1 & 2 \\
\hline \multirow[t]{4}{*}{ CT 1997} & 1 & 1 & 3 & 2 & 3 \\
\hline & 2 & 8 & 23 & 8 & 14 \\
\hline & 3 & 8 & 23 & 16 & 28 \\
\hline & 4 & 18 & 51 & 32 & 55 \\
\hline \multirow[t]{2}{*}{ CN 1997} & 0 & 15 & 43 & 27 & 47 \\
\hline & 1 & 20 & 57 & 31 & 53 \\
\hline \multirow[t]{5}{*}{ UICC 1997} & I & 4 & 11 & 7 & 12 \\
\hline & $\|$ & 3 & 9 & 7 & 12 \\
\hline & III & 9 & 26 & 12 & 20 \\
\hline & IVa & 17 & 49 & 31 & 53 \\
\hline & $\mathrm{IVb}$ & 2 & 6 & 1 & 1 \\
\hline \multirow[t]{4}{*}{ Grading } & 1 & 3 & 9 & 3 & 5 \\
\hline & 2 & 15 & 43 & 28 & 48 \\
\hline & 3 & 5 & 14 & 16 & 28 \\
\hline & 4 & 0 & - & 0 & - \\
\hline
\end{tabular}

Abbreviations: $\mathrm{R} 0$ = clear resection, $\mathrm{R} 1$ = positive margin, $\mathrm{RX}=$ resection margin uncertain.
PTV_5580 (GTV and margin) were 55.8 Gy (28.8 - 57.6 Gy; 41.4 - 59.4 Gy), respectively. Radiotherapy was not completed in four patients: two patients treated with FM developed distant metastasis during treatment (total dose 28.80 and $46.80 \mathrm{~Gy}$ ), one patient with GC received a total dose of only 41.40 Gy due to decreasing performance status and 1 patient treated with GC could not be fully treated due to cholangitis after having reached a total dose of $50.4 \mathrm{~Gy}$.

Median overall survival time for all 93 patients was 11.5 months and 12 month overall survival rate was $48 \%$. At analysis four patients were alive in the FM group and 2 in the GC group. Median overall survival for patients treated with FM was 9.7 months and 12.7 months for patients treated with GC (Figure 2). One-year overall survival rates were $40 \%$ in FM and $53 \%$ in GC treated patients and this difference was statistically significant $(\mathrm{p}$ $=0.009$ ). Survival of 36 patients who had additive chemotherapy after radiotherapy was not statistically longer than that of the 57 patients without $(\mathrm{p}=0.24)$. The vast majority of the patients died from metastatic disease. There was neither a statistically significant correlation between the use of additive chemotherapy, the dose intensity of additive chemotherapy and ECOG performance status nor between additive chemotherapy and the type of chemoradiotherapy (GC vs FM). Patients with FM and GC had a median of 7 cycles of gemcitabine.

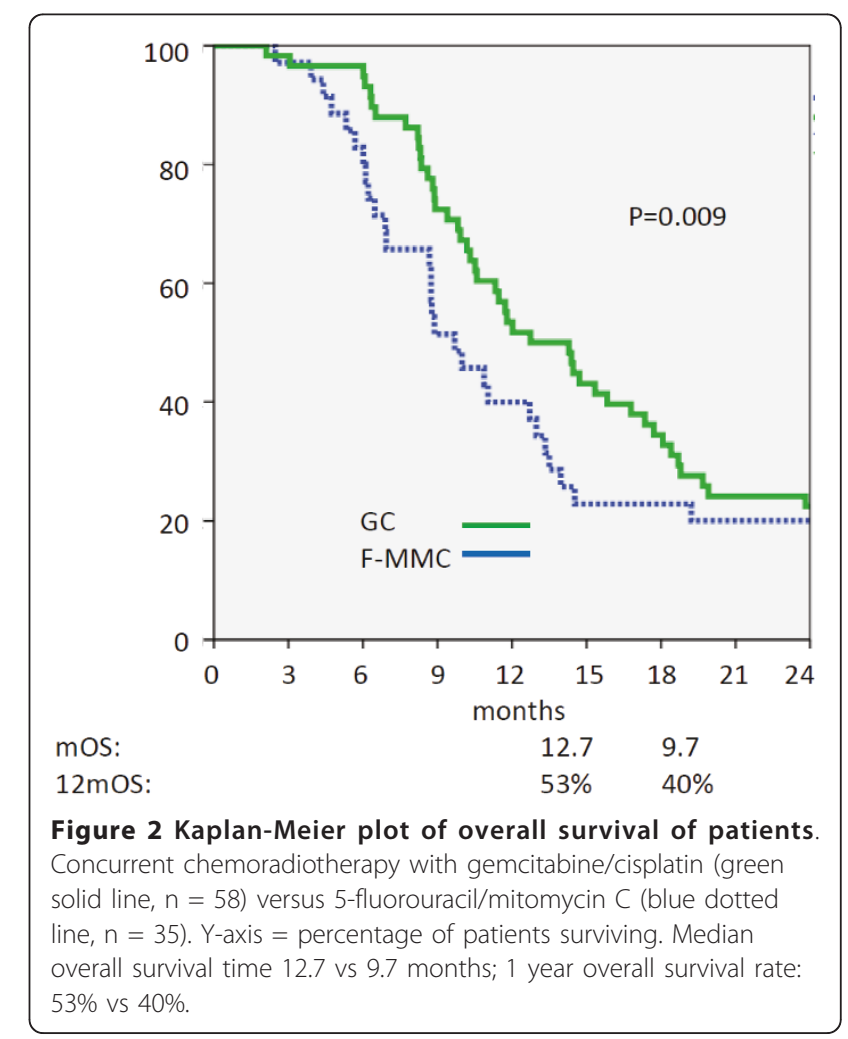




\section{Chemotherapy dose reductions and tolerance results}

As for the concurrent chemotherapy with radiotherapy, GC dose reductions were necessary in $22 \%$ of the patients. A dose reduction of FM was necessary in 14\% of the patients. The main reasons for treatment delay or dose reduction of simultaneous chemotherapy were leukocytopenia, thromocytopenia or both combined for both treatment groups.

The acute toxicities during chemoradiotherapy according to the NCI-CTC criteria are shown in Table 2. The $\mathrm{GC}$ regimen led to more grade 3 leukocytopenia and thrombocytopenia than the FM regimen, but not to more frequent grade 4 myelosuppression. Combined grade $3 / 4$ leukocytopenia of FM and GC were $37 \%$ and $48 \%$ respectively. No grade 3 or grade 4 febrile neutropenia was observed. Platelets count reduction was the most relevant grade 4 toxicity for both regimens at $11 \%$ and $12 \%$ respectively necessitating platelet prophylactic transfusions but no acute bleeding episodes were observed for both chemotherapy schedules. Combined grade $3 / 4$ thrombocytopenia was $20 \%$ vs $36 \%$, respectively in the FM and GC groups. Grade 3 upper gastrointestinal (GI) tract toxicity was more frequent with the FM regimen, again with no obvious difference for grade 4 upper GI toxicity being a rare event. Combined higher grade (3 or 4 ) nausea and vomiting were $37 \%$ vs $18 \%$ in FM and GC groups respectively. The median body mass index (BMI) was reduced by $1.0 \mathrm{~kg} / \mathrm{m}^{2}$ (standard deviation $0.98 \mathrm{~kg} / \mathrm{m}^{2}$, range $0-4.4 \mathrm{~kg} / \mathrm{m}^{2}$ ) in the GC group and $0.9 \mathrm{~kg} / \mathrm{m}^{2}$ (standard deviation $1.3 \mathrm{~kg} / \mathrm{m}^{2}$, range $-5.5-$ $2.9 \mathrm{~kg} / \mathrm{m}^{2}$ ) in the FM group at the nadir of the weight.
For the 10 patients with a BMI $<20 \mathrm{~kg} / \mathrm{m}^{2}$ the median weight loss was $0.8 \mathrm{~kg} / \mathrm{m}^{2}$ (standard deviation $0.5 \mathrm{~kg} / \mathrm{m}^{2}$, range $0-1.8 \mathrm{~kg} / \mathrm{m}^{2}$ ). We also analysed long-term toxicity: although no patients had hepatotoxicity or renal toxicity during follow up, one patient in the GC group had a duodenal bleeding from an ulcer four months after the end of therapy which was fatal. Proton pump inhibitor treatment had been discontinued after treatment despite of being prescribed in the end-of-treatment letter.

\section{Discussion}

Currently it is not clear which type of concurrent chemotherapy is best when combined with radiotherapy. While the standard of care for CRT is to combine a fluoropyrimidine with radiotherapy (5-fluorouracil or more recently also capecitabine) [10], there is a tendency to use more and more gemcitabine based chemoradiotherapy. The combination of 5-FU and mitomycin $C$ that we have used in this report was previously employed for CRT in a number of trials in PDAC [22,23,32-34]. Mitomycin C was hypothesised to be useful in addition to 5-fluorouracil because of its predominant effectiveness in hypoxic conditions [35] since severe hypoxia was shown to be present in pancreatic tumours [36]. However, after the publication of a randomised phase III trial by Burris et al. [11] showing the superiority of gemcitabine compared with fluorouracil for the treatment of patients with advanced pancreatic cancer, much effort has been made to combine gemcitabine-based regimens concurrently with radiotherapy. This is reflected by the fact that during the last decade a

Table 2 Acute toxicity of chemoradiotherapy according to CTC-NCI criteria

\begin{tabular}{|c|c|c|c|c|c|}
\hline \multirow[t]{2}{*}{ Toxicity } & & \multicolumn{2}{|c|}{ 5-FU, Mitomycin C $n=35$} & \multicolumn{2}{|c|}{ Gemcitabine, Cisplatin $n=58$} \\
\hline & CTC-Grade & & $\%$ & & $\%$ \\
\hline \multirow[t]{3}{*}{ Leukocytes } & 2 & 9 & 26 & 23 & 40 \\
\hline & 3 & 11 & 31 & 26 & 45 \\
\hline & 4 & 2 & 6 & 2 & 3 \\
\hline \multirow[t]{3}{*}{ Platelets } & 2 & 4 & 11 & 13 & 22 \\
\hline & 3 & 3 & 9 & 14 & 24 \\
\hline & 4 & 4 & 11 & 7 & 12 \\
\hline \multirow[t]{3}{*}{ Haemoglobin } & 2 & 5 & 14 & 31 & 53 \\
\hline & 3 & 3 & 9 & 2 & 3 \\
\hline & 4 & 0 & - & 0 & - \\
\hline \multirow[t]{3}{*}{ Nausea } & 2 & 11 & 31 & 23 & 40 \\
\hline & 3 & 7 & 20 & 5 & 9 \\
\hline & 4 & 0 & - & 1 & 2 \\
\hline \multirow[t]{3}{*}{ Vomiting } & 2 & 7 & 20 & 19 & 33 \\
\hline & 3 & 5 & 14 & 3 & 5 \\
\hline & 4 & 1 & 3 & 1 & 2 \\
\hline \multirow[t]{3}{*}{ Diarrhoea } & 2 & 2 & 6 & 4 & 7 \\
\hline & 3 & 0 & - & 1 & 2 \\
\hline & 4 & 0 & - & 0 & - \\
\hline
\end{tabular}


total number of 36 clinical trials using gemcitabine and chemoradiotherapy have been published in PubMed, the majority of them after 2005. The combination of gemcitabine and cisplatin concurrently with radiotherapy which we have used in this analysis was also tested in a number of CRT trials [37-40] and chemotherapy trials [41]. Preclinical studies have suggested a synergistic interaction between gemcitabine cisplatin being the result of gemcitabine incorporation into DNA and an increase of platinum -DNA adduct formation $[16,17]$. Therefore, this study reports the use of two chemotherapeutic regimens based on biological hypotheses.

One of the strengths of this retrospective comparison is the homogeneity of the treatment variables and of the selection process of the patients for definitive chemoradiotherapy within one single centre in a large number of patients. Both, median overall survival time (12.7 versus 9.7 months) and 12-month overall survival rate (53\% versus $40 \%$ ) were statistically significantly longer in the patient cohort treated with the GC regimen compared to the FM regimen. Comparing our survival results with other trials which have investigated the use of 5-fluorouracil versus gemcitabine chemoradiotherapy, Crane et al. showed a trend favouring gemcitabine (53 vs 61 patients) based CRT [42] and Li et al. reported a statistically significant survival advantage for patients treated with gemcitabine concurrently to radiotherapy over those treated with 5-fluorouracil (16 vs 18 patients) [43]. In contrast, no advantage of gemcitabine over 5-fluorouracil CRT was detected in two other trials. However, the trial reported by Brasuniene et al. was very small (10 vs 9 patients per arm) and therefore was substantially underpowered to be able to detect any difference [44]. The second negative trial, reported by Wilkowski et al. [37] compared 3 arms, 5-fluorouracil (30 patients), GC (31 patients) and GC chemoradiotherapy followed by GC chemotherapy (27 patients). As this trial is the only one using the GC combination as the here reported trial, it is worth to compare the two trials in more detail. The median overall survival rate for the GC arm and the arm with GC CRT followed by GC chemotherapy was 9.3 and 7.3 months, respectively in this study whereas we observed a median overall survival rate of 12.7 months. A hypothetical explanation for this difference is a higher total radiation dose to the primary tumour in our trial ( 55.8 Gy versus 50 Gy). The patient characteristics between the two studies were similar. However, it needs to be stressed that our analysis is retrospective in nature and therefore we cannot exclude factors such as selection bias or other inhomogeneities. We have tested known factors influencing survival as good as possible and these included TNM staging and performance status and did not observe any significant differences. Just very recently a meta-analysis on the use of gemcitabine based chemoradiotherapy compared to 5-FU including 229 patients from randomised controlled trials was published [25]. This analysis described a survival advantage of gemcitabine based chemoradiotherapy compared to 5 -Fu based for 12 month overall survival rates (RR 1.54, 95\% CI $1.05-2.26, \mathrm{p}=0.03$ ).

The toxicity analysis of the two regimens showed that the GC regimen led to a higher number of haematologic grade 3 toxicities, but interestingly not of grade 4 toxicities. Nausea and vomiting were the most frequent higher grade non-haematologic toxicities in both groups. Surprisingly, grade 3 nausea and vomiting were more frequent in the FM regimen despite of the emetogenic effect of cisplatin in the GC regimen. This might be attributable to the fact that antiemetic therapy has improved over time and FM being chronologically the first regimen used in this cohort. Comparing haematologic toxicity of the GC regimen in our trial with that reported by Wilkowski combined grade $3 / 4$ leukocytopenia was comparable ( $48 \%$ versus $52 \%$ ), grade $3 / 4$ thrombocytopenia was less frequent in our trial (36\% versus $52 \%)$ and grade $3 / 4$ nausea was comparable (11\% versus $13 \%)$. The addition of mitomycin $\mathrm{C}$ to 5 -fluorouracil in our trial led to significant differences in haematologic grade $3 / 4$ toxicity when comparing it with the Munich trial (thrombocytopenia: 20\% versus $4 \%$; leukocytopenia: $37 \%$ versus $4 \%$ ) and nausea ( $20 \%$ vs $0 \%$ ). The comparison of our study with the FFCD-SFRO [9] and with the ECOG [6] trials shows that our GC protocol resulted in lower GI toxicity compared to the ECOG regimen but more neutropenia which we attributed to the addition of cisplatin to gemcitabine. Compared with the FFCD trial our FM regimen led to a lower rate of non-haematological toxicity but a higher rate of thrombocytopenia which we attributed to the use of mitomycin $\mathrm{C}$. The above mentioned recently published meta-analysis found significant differences of leukocytopenia, thrombocytopenia and gastrointestinal bleeding being more frequent in the gemcitabine group [25]. This might be due to suboptimal radiation techniques used in the trials with the majority of the patients being treated about a decade ago. At that time the toxicity-volume relationship of gemcitabine chemoradiotherapy was not yet described as well as now and IMRT was not yet as commonly used as it is now.

\section{Conclusions}

Summarising our results in terms of efficacy and tolerance this retrospective report with its inherent limitations does not support the use of the FM regimen. Not only was it more toxic for grade 3 upper GI toxicity which is especially stressful for the patient but also less efficient and this is in line with a recent negative trial 
comparing chemoradiotherapy with radiotherapy only using this regimen [23]. On the other hand, the GC regimen was superior to FM in overall survival and reasonably well tolerated. However, tight upper limits of absolute treatment volumes have repeatedly described to be of high importance for the tolerance of gemcitabine based chemoradiotherapy regimens and we therefore advocate for very strict target volume definitions $[27,45]$. Last but not least it should be mentioned that currently the SCALOP trial in the UK compares gemcitabine vs. capecitabine based chemoradiotherapy in a randomised controlled phase II trial from which we expect will allow to draw firmer conclusions in the near future.

\section{Acknowledgements}

Supported by the University Hospitals of Erlangen

\section{Author details}

'Radiation Oncology of the Friedrich-Alexander University of ErlangenNuremberg, Universitätsstraße 22, 91054 Erlangen, Germany. ${ }^{2}$ Gray Institute for Radiation Oncology and Biology, University of Oxford, Roosevelt Drive, Oxford OX3 7DQ, UK.

\section{Authors' contributions}

TBB: Performed the retrospective analysis. TBB, RS, RF: developed the chemotherapeutic protocols. All the listed authors have been involved in drafting or in revising the manuscript. All authors read and approved the final manuscript.

\section{Competing interests}

The authors declare that they have no competing interests.

Received: 2 May 2011 Accepted: 27 July 2011 Published: 27 July 2011

\section{References}

1. UK cancer mortality statistics for common cancers. [http://info. cancerresearchuk.org/cancerstats/mortality/cancerdeaths/?a=5441].

2. Malvezzi M, Arfe A, Bertuccio P, Levi F, La Vecchia C, Negri E: European cancer mortality predictions for the year 2011. Ann Oncol 2011, 22(4):947-956.

3. Hidalgo M: Pancreatic cancer. N Engl J Med 2010, 362(17):1605-1617.

4. Brunner TB, Scott-Brown M: The role of radiotherapy in multimodal treatment of pancreatic carcinoma. Radiation oncology (London, England) 2010, 5:64.

5. Huguet F, Andre T, Hammel P, Artru P, Balosso J, Selle F, DeniaudAlexandre E, Ruszniewski P, Touboul E, Labianca R, et al: Impact of chemoradiotherapy after disease control with chemotherapy in locally advanced pancreatic adenocarcinoma in GERCOR phase II and III studies. J Clin Oncol 2007, 25(3):326-331.

6. Loehrer PJ, Powell ME, Cardenes HR, Wagner L, Brell JM, Ramanathan RK, Crane $\mathrm{CH}$, Alberts SR, Benson AB: A randomized phase III study of gemcitabine in combination with radiation therapy versus gemcitabine alone in patients with localized, unresectable pancreatic cancer: E4201. Clin Oncol 2008, 26(suppl):1.

7. Gillen S, Schuster T, Meyer Zum Buschenfelde C, Friess $\mathrm{H}$, Kleeff $\mathrm{J}$ : Preoperative/neoadjuvant therapy in pancreatic cancer: a systematic review and meta-analysis of response and resection percentages. PLOS medicine 2010, 7(4):e1000267.

8. Tinkl D, Grabenbauer GG, Golcher H, Meyer T, Papadopoulos T, Hohenberger W, Sauer R, Brunner TB: Downstaging of pancreatic carcinoma after neoadjuvant chemoradiation. Strahlenther Onkol 2009, 185(9):557-566.

9. Chauffert B, Mornex F, Bonnetain F, Rougier P, Mariette C, Bouche O, Bosset JF, Aparicio T, Mineur L, Azzedine A, Hammel P, Butel J, Stremsdoerfer N, Maingon P, Bedenne L: Phase III trial comparing intensive induction chemoradiotherapy (60 Gy, infusional 5-FU and intermittent cisplatin) followed by maintenance gemcitabine with gemcitabine alone for locally advanced unresectable pancreatic cancer. Definitive results of the 2000-01 FFCD/SFRO study. Ann Oncol 2008.

10. van Moorsel CJ, Pinedo HM, Veerman G, Guechev A, Smid K, Loves WJ, Vermorken JB, Postmus PE, Peters GJ: Combination chemotherapy studies with gemcitabine and etoposide in non-small cell lung and ovarian cancer cell lines. Biochem Pharmacol 1999, 57(4):407-415.

11. Burris HA III, Moore MJ, Andersen J, Green MR, Rothenberg ML, Modiano MR, Cripps MC, Portenoy RK, Storniolo AM, Tarassoff P, Nelson R, Dorr FA, Stephens CD, Von Hoff DD: Improvements in survival and clinical benefit with gemcitabine as first-line therapy for patients with advanced pancreas cancer: a randomized trial. JClinOncol 1997, 15(6):2403-2413.

12. Shewach DS, Lawrence TS: Antimetabolite radiosensitizers. J Clin Oncol 2007, 25(26):4043-4050.

13. Okazaki T, Jiao L, Chang P, Evans DB, Abbruzzese JL, Li D: Single-nucleotide polymorphisms of DNA damage response genes are associated with overall survival in patients with pancreatic cancer. Clin Cancer Res 2008, 14(7):2042-2048

14. Raut $\mathrm{CP}$, Evans $\mathrm{DB}$, Crane CH, Pisters PW, Wolff RA: Neoadjuvant therapy for resectable pancreatic cancer. Surg Oncol Clin N Am 2004, 13(4):639-661, ix

15. Talamonti MS, Catalano PJ, Vaughn DJ, Whittington R, Beauchamp RD, Berlin J, Benson AB: Eastern Cooperative Oncology Group Phase I trial of protracted venous infusion fluorouracil plus weekly gemcitabine with concurrent radiation therapy in patients with locally advanced pancreas cancer: a regimen with unexpected early toxicity. J Clin Oncol 2000, 18(19):3384-3389.

16. Symon Z, Davis M, McGinn CJ, Zalupski MM, Lawrence TS: Concurrent chemoradiotherapy with gemcitabine and cisplatin for pancreatic cancer: from the laboratory to the clinic. Int I Radiat Oncol Biol Phys 2002, 53(1):140-145

17. van Moorsel CJ, Pinedo HM, Veerman G, Bergman AM, Kuiper CM, Vermorken JB, van der Vijgh WJ, Peters GJ: Mechanisms of synergism between cisplatin and gemcitabine in ovarian and non-small-cell lung cancer cell lines. Br J Cancer 1999, 80(7):981-990.

18. Gregoire V, Cvilic S, Beauduin M, De Coster B, Gueulette J, OctavePrignot $\mathrm{M}$, Scalliet $\mathrm{P}$ : Effect of gemcitabine on the tolerance of the lung to single-dose irradiation in C3H mice. Radiat Res 1999, 151(6):747-749.

19. Heinemann V, Boeck S, Hinke A, Labianca R, Louvet C: Meta-analysis of randomized trials: evaluation of benefit from gemcitabine-based combination chemotherapy applied in advanced pancreatic cancer. BMC Cancer 2008, 8:82.

20. Crane $\mathrm{CH}$, Janjan NA, Evans DB, Wolff RA, Ballo MT, Milas L, Mason $\mathrm{K}$, Charnsangavej C, Pisters PW, Lee JE, Lenzi R, Vauthey J, Wong A, Phan T, Nguyen Q, Abbruzzese J: Toxicity and efficacy of concurrent gemcitabine and radiotherapy for locally advanced pancreatic cancer. IntJPancreatol 2001, 29(1):9-18

21. Eppinga W, Lagerwaard F, Verbakel W, Slotman B, Senan S: Volumetric modulated arc therapy for advanced pancreatic cancer. Strahlenther Onkol 2010, 186(7):382-387.

22. Hoffman JP, Lipsitz S, Pisansky T, Weese JL, Solin L, Benson AB III: Phase II trial of preoperative radiation therapy and chemotherapy for patients with localized, resectable adenocarcinoma of the pancreas: an Eastern Cooperative Oncology Group Study. JClinOncol 1998, 16(1):317-323

23. Cohen SJ, Dobelbower R Jr, Lipsitz S, Catalano PJ, Sischy B, Smith TJ, Haller DG: A randomized phase III study of radiotherapy alone or with 5fluorouracil and mitomycin- $\mathrm{C}$ in patients with locally advanced adenocarcinoma of the pancreas: Eastern Cooperative Oncology Group study E8282. Int J Radiat Oncol Biol Phys 2005, 62(5):1345-1350.

24. Wolf $M$, Zehentmayr $F$, Niyazi M, Ganswindt U, Haimerl W, Schmidt M, Holzel D, Belka C: Long-term outcome of mitomycin C- and 5-FU-based primary radiochemotherapy for esophageal cancer. Strahlenther Onkol 2010, 186(7):374-381

25. Zhu CP, Shi J, Chen YX, Xie WF, Lin Y: Gemcitabine in the chemoradiotherapy for locally advanced pancreatic cancer: A metaanalysis. Radiother Oncol 2011, 99(2):108-113.

26. NCCN Clinical Practice Guidelines in Oncology. Pancreatic Adenocarcinoma. v.1.2008. [http://www.nccn.org].

27. Brunner TB, Merkel S, Grabenbauer GG, Meyer T, Baum U, Papadopoulos T, Sauer $R$, Hohenberger W: Definition of elective lymphatic target volume 
in ductal carcinoma of the pancreatic head based upon histopathologic analysis. IntJRadiatOncolBiolPhys 2005, 62(4):1021-1029.

28. Japanese Gastric Cancer A: Japanese Classification of Gastric Carcinoma 2nd English Edition. Gastric Cancer 1998, 1(1):10-24.

29. Brunner TB, Grabenbauer GG, Klein P, Baum U, Papadopoulos T, Bautz W, Hohenberger W, Sauer R: Phase I trial of strictly time-scheduled gemcitabine and cisplatin with concurrent radiotherapy in patients with locally advanced pancreatic cancer(1). Int/RadiatOncolBiolPhys 2003, 55(1):144-153

30. Cox JD, Stetz J, Pajak TF: Toxicity criteria of the Radiation Therapy Oncology Group (RTOG) and the European Organization for Research and Treatment of Cancer (EORTC). Int I Radiat Oncol Biol Phys 1995, 31(5):1341-1346

31. Rubin $\mathrm{P}$, Constine $L S$, Fajardo LF, Phillips TL, Wasserman TH: RTOG Late Effects Working Group. Overview. Late Effects of Normal Tissues (LENT) scoring system. Int J Radiat Oncol Biol Phys 1995, 31(5):1041-1042.

32. Whittington R, Bryer MP, Haller DG, Solin L, Rosato EF: Adjuvant therapy of resected adenocarcinoma of the pancreas. IntJRadiatOncolBiolPhys 1991, 21(5):1137-1143.

33. Yeung RS, Weese JL, Hoffman JP, Solin LJ, Paul AR, Engstrom PF, Litwin S, Kowalyshyn MJ, Eisenberg BL: Neoadjuvant chemoradiation in pancreatic and duodenal carcinoma. A Phase II Study. Cancer 1993, 72(7):2124-2133.

34. Hoffman JP, Weese JL, Solin LJ, Engstrom P, Agarwal P, Barber LW, Guttmann MC, Litwin S, Salazar H, Eisenberg BL: A pilot study of preoperative chemoradiation for patients with localized adenocarcinoma of the pancreas. AmJSurg 1995, 169(1):71-77.

35. Krishna MC, DeGraff W, Tamura S, Gonzalez FJ, Samuni A, Russo A, Mitchell JB: Mechanisms of hypoxic and aerobic cytotoxicity of mitomycin C in Chinese hamster V79 cells. Cancer research 1991, 51(24):6622-6628.

36. Koong AC, Mehta VK, Le QT, Fisher GA, Terris DJ, Brown JM, Bastidas AJ, Vierra M: Pancreatic tumors show high levels of hypoxia [In Process Citation]. Int/RadiatOncolBiolPhys 2000, 48(4):919-922.

37. Wilkowski R, Boeck S, Ostermeier S, Sauer R, Herbst M, Fietkau R, Flentje M, Bruns $C J$, Rau HG, Heinemann V: Final analysis of a multicenter, randomized phase II trial comparing three different chemoradiotherapy regimens in the treatment of patients with locally advanced, nonmetastatic pancreatic cancer. J Clin Oncol 2009, 27(15s):4610, abstr.

38. Wilkowski R, Thoma M, Duhmke E, Rau HG, Heinemann V: Concurrent chemoradiotherapy with gemcitabine and cisplatin after incomplete (R1) resection of locally advanced pancreatic carcinoma. Int I Radiat Oncol Biol Phys 2004, 58(3):768-772.

39. Haddock MG, Swaminathan R, Foster NR, Hauge MD, Martenson JA, Camoriano JK, Stella PJ, Tenglin RC, Schaefer PL, Moore DF Jr, Alberts SR: Gemcitabine, cisplatin, and radiotherapy for patients with locally advanced pancreatic adenocarcinoma: results of the North Central Cancer Treatment Group Phase II Study N9942. J Clin Oncol 2007, 25(18):2567-2572.

40. Muler JH, McGinn CJ, Normolle D, Lawrence T, Brown D, Hejna G, Zalupski MM: Phase I trial using a time-to-event continual reassessment strategy for dose escalation of cisplatin combined with gemcitabine and radiation therapy in pancreatic cancer. JClinOncol 2004, 22:238-243.

41. Heinemann V, Labianca R, Hinke A, Louvet C: Increased survival using platinum analog combined with gemcitabine as compared to singleagent gemcitabine in advanced pancreatic cancer: pooled analysis of two randomized trials, the GERCOR/GISCAD intergroup study and a German multicenter study. Ann Oncol 2007, 18(10):1652-1659.

42. Crane $\mathrm{CH}$, Abbruzzese JL, Evans DB, Wolff RA, Ballo MT, Delclos M, Milas L, Mason K, Charnsangavej C, Pisters PW, et al: Is the therapeutic index better with gemcitabine-based chemoradiation than with 5 -fluorouracilbased chemoradiation in locally advanced pancreatic cancer? Int I Radiat Oncol Biol Phys 2002, 52(5):1293-1302.

43. Li CP, Chao Y, Chi KH, Chan WK, Teng HC, Lee RC, Chang FY, Lee SD, Yen SH: Concurrent chemoradiotherapy treatment of locally advanced pancreatic cancer: gemcitabine versus 5-fluorouracil, a randomized controlled study. Int I Radiat Oncol Biol Phys 2003, 57(1):98-104.

44. Brasiuniene B, Juozaityte $E$ : The effect of combined treatment methods on survival and toxicity in patients with pancreatic cancer. Medicina (Kaunas) 2007, 43(9):716-725.

45. Crane $\mathrm{CH}$, Wolff RA, Abbruzzese JL, Evans DB, Milas L, Mason K, Charnsangavej C, Pisters PW, Lee JE, Lenzi R, Lee JE, Lenzi R, Vauthey JN,
Wong $A B$, Phan $T$, Nguyen $Q$, Janjan NA: Combining gemcitabine with radiation in pancreatic cancer: understanding important variables influencing the therapeutic index. SeminOncol 2001, 28(3 Suppl 10):25-33.

doi:10.1186/1748-717X-6-88

Cite this article as: Brunner et al:: Gemcitabine/cisplatin versus 5fluorouracil/mitomycin C chemoradiotherapy in locally advanced pancreatic cancer: a retrospective analysis of 93 patients. Radiation Oncology 2011 6:88.

\section{Submit your next manuscript to BioMed Central and take full advantage of:}

- Convenient online submission

- Thorough peer review

- No space constraints or color figure charges

- Immediate publication on acceptance

- Inclusion in PubMed, CAS, Scopus and Google Scholar

- Research which is freely available for redistribution

Submit your manuscript at www.biomedcentral.com/submit
Biomed Central 